International Journal of Engineering \& Technology, 7 (3.34)(2018) $397-401$
International Journal of Engineering \& Technology
SPC
Website: www.sciencepubco.com/index.php/IJET
Research paper

\title{
Design and Analysis of Battery Box Lifter
}

\author{
Karthick $\mathrm{N}^{1^{*}}$, Aravindh $\mathrm{S}^{2}$, Gayathri $\mathrm{N}^{3}$, Nagendran $\mathrm{N}^{4}$, Siddaarthan $\mathrm{K}^{5}$, Thenamuthan $\mathrm{A}^{6}$ \\ 1,2,3,4,5,6 Department of Mechanical Engineering, Vel Tech High Tech Dr.Rangarajan Dr.Sakunthala Engineering College, \\ Chennai - 600062, India \\ *Corresponding author E-mail: karthick.mech1987@gmail.com
}

\begin{abstract}
The main objective of this project is to design and analyze the portable hydraulic scissor truck instead of manual pallet truck for the purpose of dropping and lifting battery box in AC Coaches to bring it outside for checking suspension/cradle of battery box for availability of all suspension bolts, signs of any cracks, corrosion, rusting and taking corrective action, if necessary. If suitable hydraulic cylinder with more power is used, this scissor lift can also be designed for heavy load purposes. This equipment will be simple to use. Frequent maintenance is not required for this equipment. In this paper we carried out detailed analysis of scissor mechanism members against bending and buckling failure and also focused on various design aspects and working of scissor mechanism and helpful to lifting and dropping of battery box without any failure with this scissor truck For existing practice the battery box dropping and lifting done by using manual pallet truck. It shows the design is unsafe handling, injury to employee and feel uncomfortable. It is very tedious for human being to lift a vehicle above from the ground. Even when a hydraulic jack is implemented, it requires manual work. In this era, every man in the world wants comfort and hence to relieve the problems faced by lifting and placing the battery box. Our project aims to reduce the manual work involved during the replacement of battery box instead of applying manual pallet truck. To validate our point and to reduce the above said difficulties faced, the design of hydraulic lift has been changed.
\end{abstract}

Keywords: Air strainer; Human Error; Scissor Lift; Semi automatic method; Test rig

\section{Introduction}

In Indian Railways AC Coach, the battery is fixed underneath inside a battery box. The battery performs in varying atmospheres like dust, vibration, temperature, restricted maintenance time and continuous discharging mode.

For that in every periodic overhauling (POH), we are going to drop the battery box, bring it outside and check suspension/cradle, suspension bolts, signs of any crack, corrosion, rusting and take corrective action necessary. After finishing the battery box is lifted to the coaches.

For existing practice it can be done by using pallet truck. The pallet truck will gives unbalance to lift or drop the battery box, that unbalance will affect unsafe handling, injury to employee and takes more time. Instead of using pallet truck we are going to design the hydraulic scissor lift or truck.

This can be done by hydraulic piston and scissor lift. These hydraulic systems are used mostly in transportation, aviation equipments, machine tools, etc.

\subsection{Types of Lifting Devices}

Mechanical Jacks usually have high lifting capacity.

i. Screw jack

ii. Scissor jack

iii. Floor jack

iv. Pallet jack

\subsection{Drawback with Pallet Jack}

- More wear of parts

- Heavy effort needed to operate

- Positioning of jack in exact position is cumbersome

- Unsafe handling

- Unbalance lifting

\subsection{Alternate Method}

To overcome the above drawbacks hydraulic scissor truck (lift) is used.

\subsection{Hydraulic Jack (Lift)}

The hydraulic jack is placed underneath the vehicle. Manual effort is required to operate the lever and to lift the battery box. So, if someone uses automatic operations, these difficulties can be overcome and time can be saved.

The braking mechanism used in hydraulic brakes consists of brake fluid, mostly ethylene glycol which enables to move the pressure from the control unit. This control unit is located near the operator who operates the vehicle. Real brake mechanism is located at or very near to the vehicle wheel.

\subsection{Design of the Scissor Lift}

Floor space area provided $2.1 \mathrm{~m}$ x $0.87 \mathrm{~m}$ Technical Specification of the lift is: 
Loading capacity - $1000 \mathrm{Kg}$

Height of rise $-430 \mathrm{~mm}$

Rise time - 40sec

Lowering time - 40sec

Initial height $-0 \mathrm{~mm}$ (ground level)

Total Mass - $2100 \mathrm{Kg}$

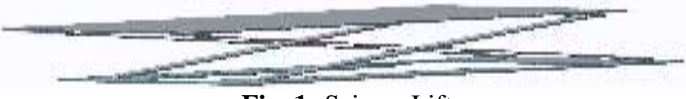

Fig. 1: Scissor Lift

\section{Design Calculation}

In design calculations, the design concepts are discussed. Depending upon the evaluation criteria, the design is modified further to increase the workability of the designed model. The following are the design considerations made during the process of designing and fabrication of the single acting cylinder.

Functionality of the design

Manufacturability

- Cost

- Availability

\subsection{The Total Load of the Scissor Truck:}

Mass to be put on the lift is $375 \mathrm{Kg}$

For mass in pallet,

Taking FOS as 1.5,

$1000 \mathrm{x} 1.5=1500 \mathrm{Kg}$

Top frame mass is 360 Kilograms

Each arm of scissor mass is $53.57 \mathrm{Kg}$

Total mass of four Scissor arms is $214.28 \mathrm{Kg}$

Cylinder mounting link mass is $8 \mathrm{Kg}$

Cylinder mass is $18 \mathrm{Kg}$

So, Total mass is $2100.28 \mathrm{Kg}$

Total Calculated load is $2100.28 \times 9.81=20603.7468 \mathrm{~N}$

The force essential to uplift the load in a scissor lift is completely depend upon angle of link, length of link and cylinder mounting on the link,

Formula used:

End point distance, $\mathrm{S}=\mathrm{L}^{2}+\mathrm{a}^{2}-2 \mathrm{a} \mathrm{L}^{*} \operatorname{Cos} \alpha$

Scissor arm length is $1.3 \mathrm{~m}$

Angle of the cylinder with the horizontal link is $\alpha$.

If cylinder is closed position, i.e, when the links of scissor are shut down, full force will be acting on the cylinder.

For calculations,

Let us consider $\alpha$ is 30

Thus, we get

$\mathrm{F}$ as $20603.7468 \mathrm{~N}$

Selecting the cylinder with bore diameter of $60 \mathrm{~mm}$

Bore of the cylinder $=(3.14 * 602) / 2=5652 \mathrm{~mm}^{2}$

Pressure $=(\mathrm{F} / \mathrm{A})=(20603.7468 / 5652 \times 106)==36.4 \mathrm{bar}$

\section{Methodology}

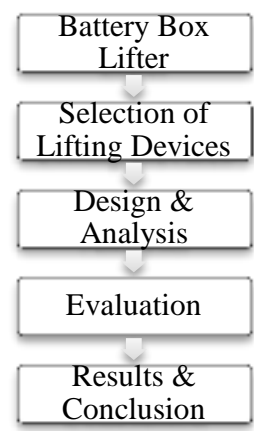

Fig. 2: Proposed Methodology
If the load is applied or removed, every part in the scissor lift has the capacity to accumulate or discharge energy when there is a process of loading and unloading. The deflection can be explained as the variations of all structures to the actual size of the battery box. It takes place in all places of lift i.e. Legs, Base, Structure, and Pinned Joints. In order to decrease the stress level and the redirection in the scissor lift, the force will be moving wih reference to scissor arm pair equally.

\section{Design and Analysis}

\subsection{CAD Model}

\section{i) Pallet truck}

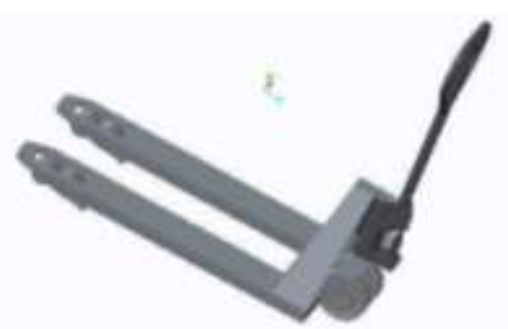

Fig. 3: Pallet Truck

ii) Hydraulic Lifting Scissor Truck

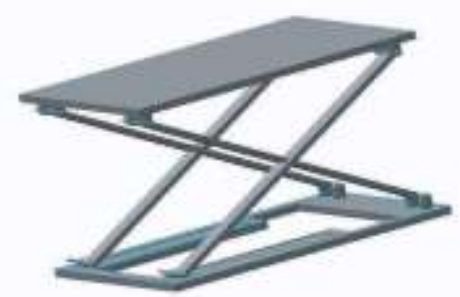

Fig. 4: Hydraulic Scissor Truck

\subsection{Modelling of Scissor Truck}

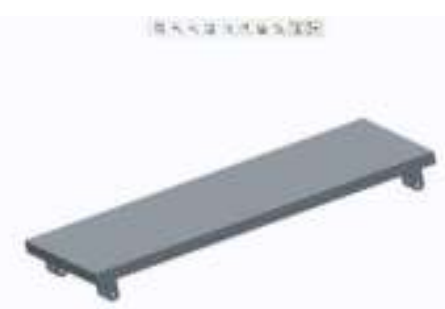

Fig. 5: Top Platform

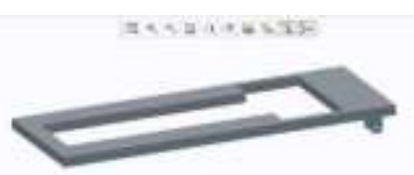

Fig. 6: Base Frame

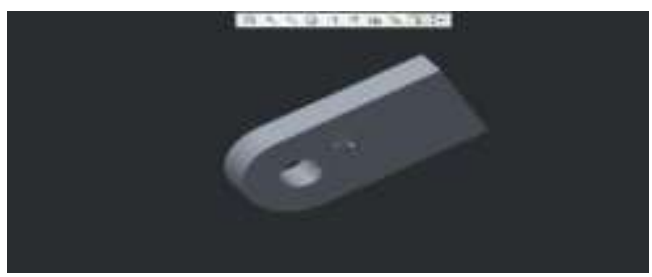

Fig. 7: Support Hinge 


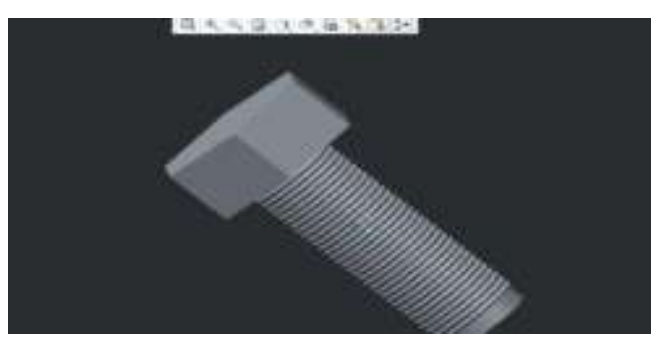

Fig. 8: Bolt

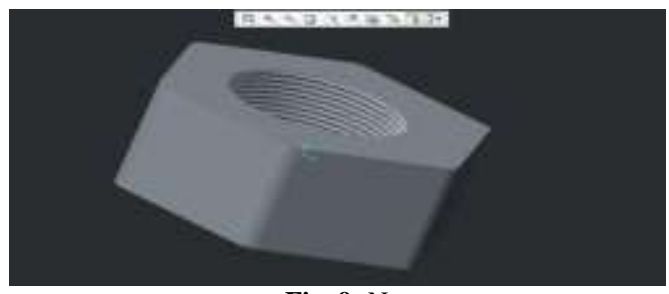

Fig. 9: Nut

\subsection{Analysis of the Design}

Equipment design with Software Many kinds of constructions exists for the scissors lift platform, but the main constituents of all lift platform are the upper platform, number of pairs of scissors and the bottom platform. In our design we have used wheels with motors attached to it at back for movement from one place to other. The numbers of the scissors pairs and the position of the hydraulic cylinders even have different positions, which lead to different lifting height of the platform. We achieve height of $1 \mathrm{~m}$ for the upper platform from base. Upper platform dimension is about $2100 \times 870 \mathrm{~mm}^{2}$ which is enough for carrying bigger rated loading capacity.

There are three ways for the bottom platform to move as for dragging, automatic control through remote and force application at back. The bottom platform is designed so as to have pair of scissors mechanisms held symmetrically.

Scissor lift has two plates elevated on top of each other parallel to each other through the actuators, with small one on upside and large one is on conveyor railing.

Small one is for lifting the load vertically. Large one is for horizontal movement. Actuator is also attached. Geometric specifications were selected in order to bear standard trolley. By the application of design and analysis software, components can be designed and analysis can be done.

ANSYS Procedure for Static Analysis:

- FE model is built

- Material Properties is listed

- Boundary Condition is applied

- Using LS Command from the ANSYS, problem is solved.

Material Properties of Mild Steel Lift Lift:

- E, Young's modulus is $210 \mathrm{MPa}$

- NUXY, Poisson's ratio is 0.303

- Mass density is $7860 \mathrm{Kg} / \mathrm{m}^{3}$

- Co-efficient of Damping is 0.008

Summary for Optimization of Design:

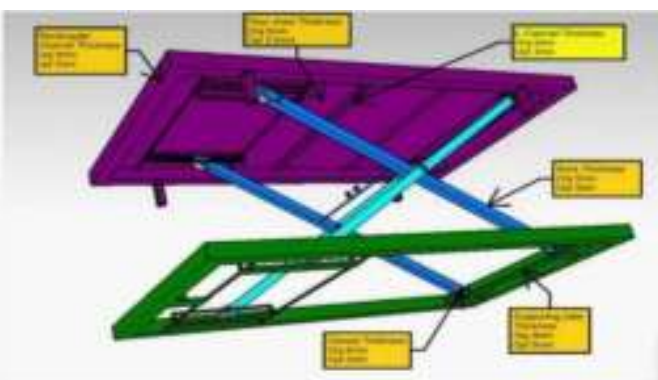

Fig. 11: Optimization of Design

\subsubsection{ANSYS Report of Pallet Truck:}

Our proposed mechanism was designed using CREO 2.0. Then it was analyzed in ANSYS under variable loading.

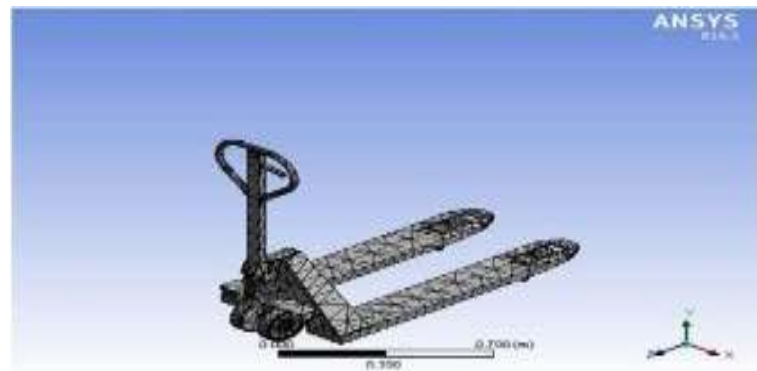

Fig. 12: Mesh

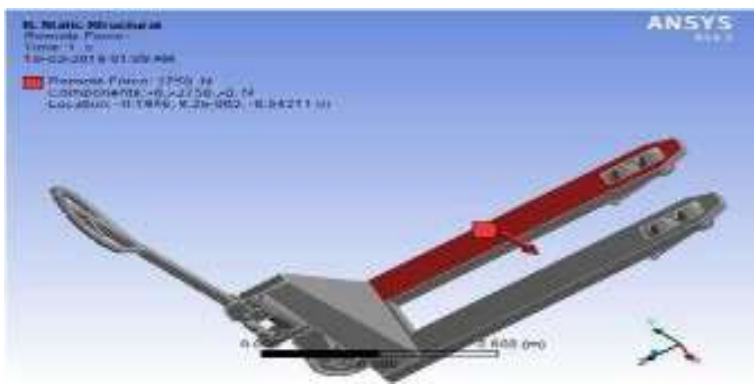

Fig. 13: Force

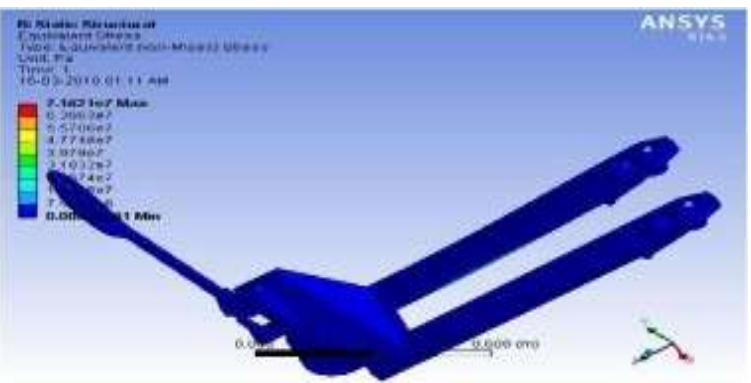

Fig. 14: Equivalent stress

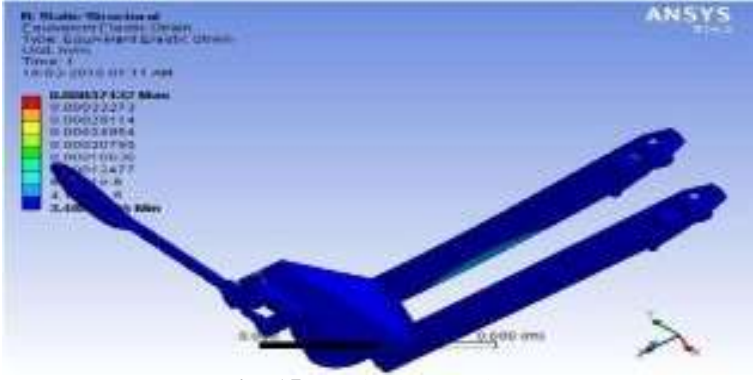

Fig. 15: Equivalent strain

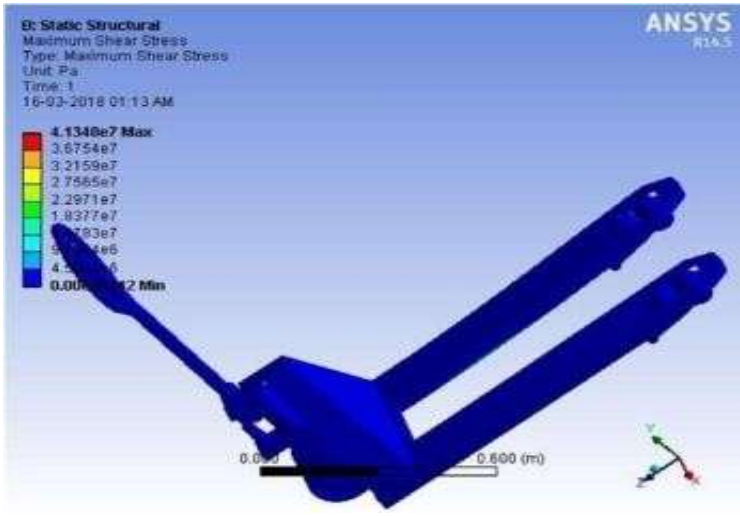

Fig. 16: Maximum shear stress 


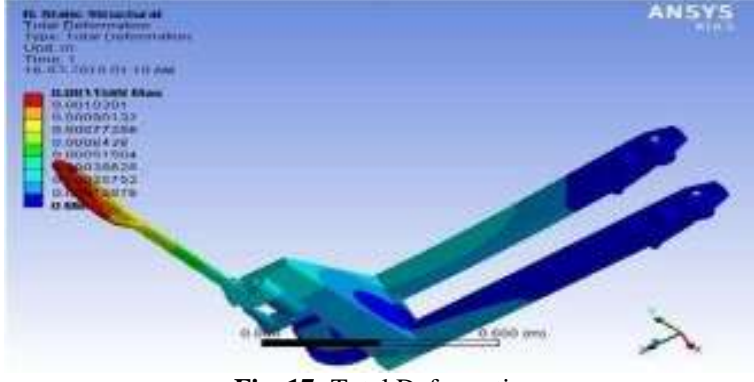

Fig. 17: Total Deformation

\subsubsection{ANSYS Report of Hydraulic Scissor Truck}

Our proposed mechanism was designed using CREO 2.0. Then it was analyzed in ANSYS under variable loading.

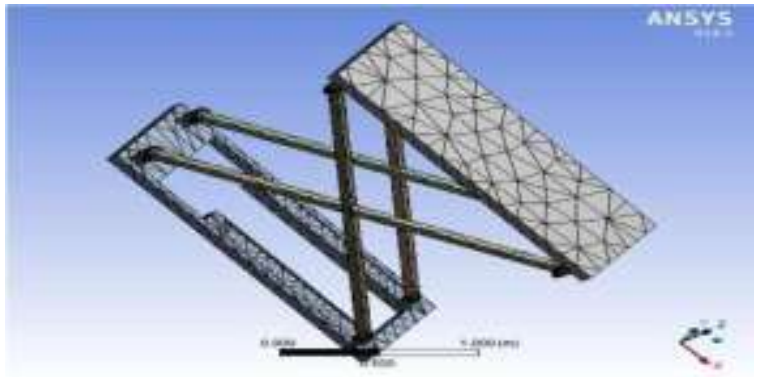

Fig. 18: Mesh

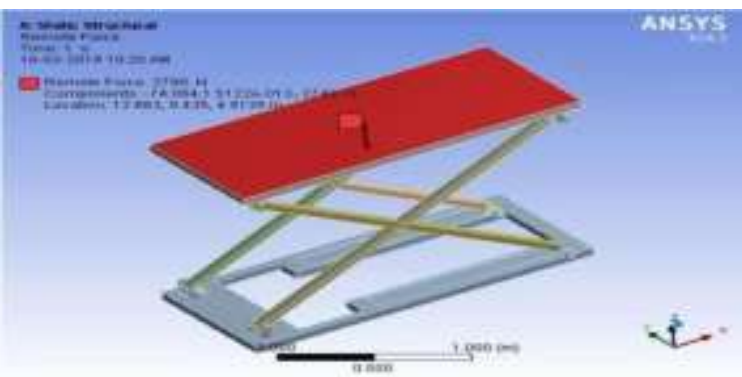

Fig. 19: Force

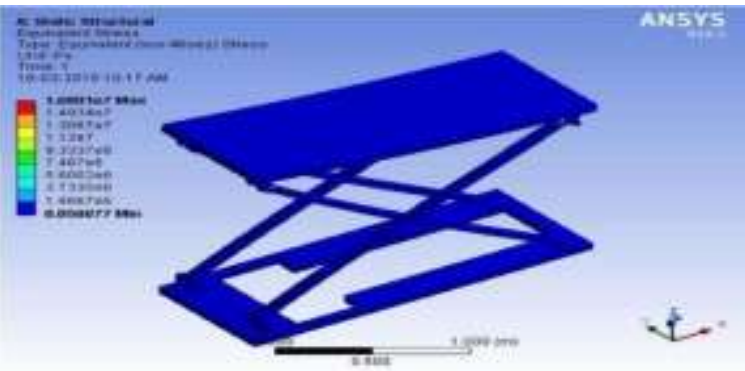

Fig. 20: Equivalent Stress

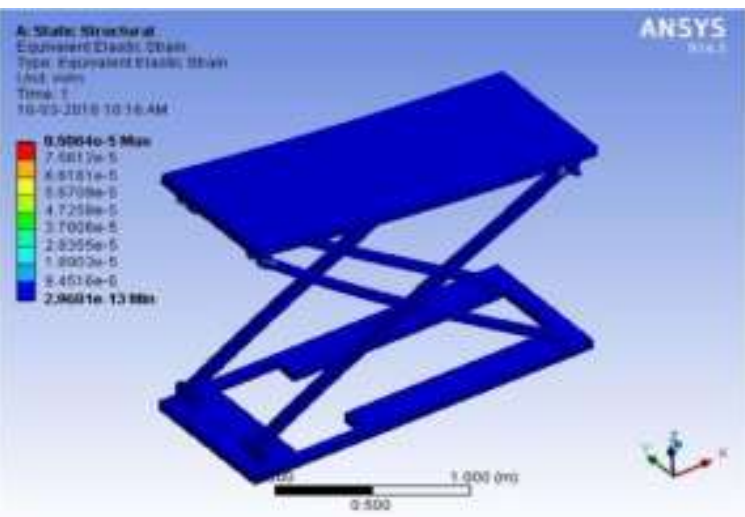

Fig. 21: Equivalent Strain

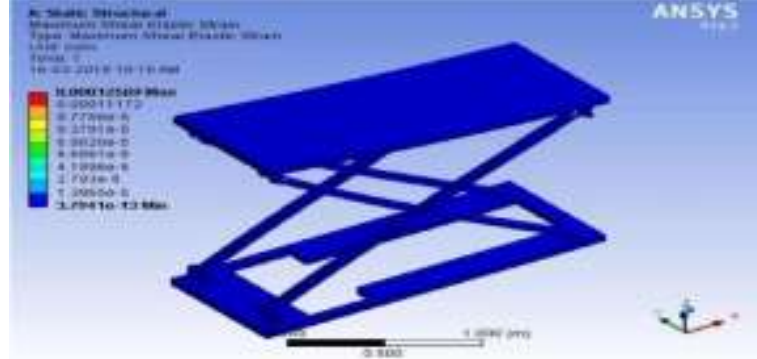

Fig. 22: Maximum Shear Stress

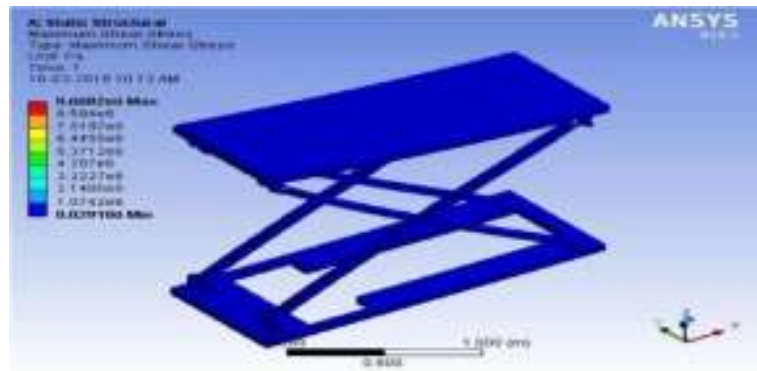

Fig. 23: Maximum Shear Strain

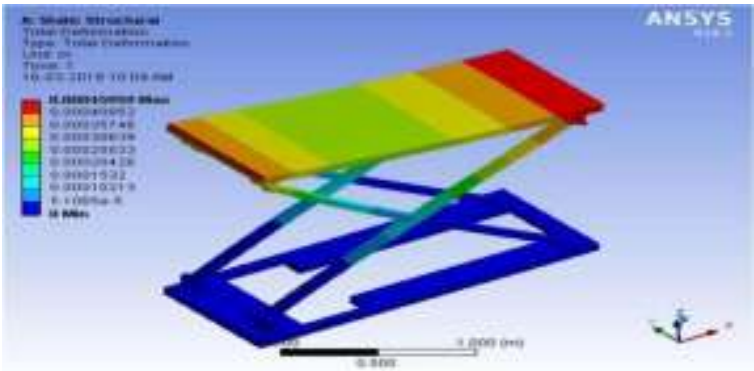

Fig. 24: Total Deformation

\section{Results and Discussions}

\begin{tabular}{|c|c|c|}
\hline LOAD FACTOR & PALLET TRUCK & SCISSOR TRUCK \\
\hline Max Shear Stress & $4.134 \times 10^{7} \mathrm{~Pa}$ & $9.6682 \times 10^{7} \mathrm{~Pa}$ \\
\hline Max Shear Strain & 0.000537 & 0.00012569 \\
\hline Max Equivalent Stress & $7.1621 \times 10^{7} \mathrm{~Pa}$ & $1.601 \times 10^{7} \mathrm{~Pa}$ \\
\hline Max Equivalent Strain & 0.00037432 & 0.0000851 \\
\hline Total Deformation & $0.0011588 \mathrm{~m}$ & $0.00045959 \mathrm{~m}$ \\
\hline
\end{tabular}

The pallet truck and scissor truck modeling and analysis had been done. Both designs are safe. In max shear stress, max shear strain, max equivalent stress, max equivalent strain, total deformation in the scissor truck is better than pallet truck.

\section{Conclusion}

This Project focuses on various aspects related to lifting mechanism and its design. The Static analysis reflects that the selected mechanism is functional and most likely reliable for its purpose. Motor operates an hydraulic cylinder which inturn operates the portable work platform.. Also whole device is motorized and with help of control panel allows user to travel from one place to other. The scissor lift can be designed for high load also if a suitable high capacity hydraulic cylinder is used. The hydraulic scissor lift is simple in use and does not require routine maintenance. In this paper we carried out detailed analysis of scissor mechanism members against bending and buckling failure and also focused on various design aspects and working of scissor mechanism and helpful to lift and drop of battery box without any failure with this scissor truck. 


\section{References}

[1] "Analysis \& Optimization of Hydraulic Scissor Lift", Sabde Abhijit Manoharrao, Prof. Jamgekar R.S. 2016 IJEDR Volume 4, Issue 4 | ISSN:2321-9939

[2] "Design, Manufacturing \& Analysis of Hydraulic Scissor Lift" Gaffar G Momin, et al, International Journal Of Engineering Research And General Science Volume 3, Issue 2, Part 2, March-April, 2015

[3] "Design, Analysis and Development of Multiutility home equipment using Scissor Lift Mechanism", Divyesh Prafulla Ubale et al. Volume-3, Issue - 3, Pages- 2405-2408, 2015

[4] "Design and Analysis of Hydraulic Pallet System in Chain Conveyor" Setu Dabhi, et al, IJRET: International Journal of Research in Engineering and Technology eISSN: 2319-1163 ISSN: 2321-7308

[5] "Design and analysis of an aerial scissor Lift" M. Abhinay, P.Sampath Rao SSRG International Journal of Mechanical Engineering (SSRG-IJME) - volume1 issue 5 September2014

[6] "Design and Analysis of an Aerial Scissor Lift", Soma Raghavendra, C. Raghunath ReddyInternational Journal of Engineering Science and Computing, July 2017

[7] "Design and Construction of Hydraulic Scissor Lift", Sandeep G. Thorat, Abhijeet R. Chiddarwarand Suva Prasana Prusty MITCOE, \& DIAT, Pune, AMET-2017, IJCET INPRESSO Special Issue-7 (March 2017)

[8] "Design \& Analysis of Hydraulic Scissor Lift M. Kiran Kumar, J.Chandrasheker, Mahipal Manda, D.VijayKumar International Research Journal of Engineering and Technology (IRJET), Volume: 03 Issue: 06 June-2016

[9] "Design and Fabrication of Hydraulic Scissor Lift", Doli Rani, Nitin Agarwal, MIT Journal of Mechanical Engineering, Vol. 5, No. 2, August 2015, pp. 81-87 81 ISSN 2230-7680

[10] "Design and Calculation of the Scissors- Type Elevating Platforms" Beqir Hamid Beograd 1995. 